\title{
Perceived barriers to entry to the eating disorder specialty within the dietetics profession and differences by race $\&$ ethnicity: results of a cross-sectional survey.
}

\author{
Megan Bradshaw, MS; Sienna Caron, MS; Lisa S. Brown PhD, RD, LDN
}

\begin{abstract}
Specializing in treatment of eating disorders requires additional training for a Registered Dietitian (RD). Added barriers to specializing in eating disorder treatment may disproportionately affect dietitians from underrepresented race/ethnicity groups, discouraging entering the specialty. This cross-sectional study aimed to identify potential barriers for registered dietitians pursuing a specialty in eating disorder treatment, and compare barriers identified by RDs from underrepresented race/ethnicity groups in the profession to RDs who self-identify as white. A random sample of US dietitians were sent an electronic survey regarding their experience with entering this specialty. Common barriers identified through a review of literature were listed for participants to select and free response boxes were available to provide additional information. Free responses were coded and frequencies were calculated for both white participants and participants who identified as a person of color. Differences in the frequency of cited barriers between the two groups were analyzed using chi-squares. In our final sample $(n=328) \quad 1 / \%$ of dietitians self-identified as coming from an under-represented demographic in the profession, while $88.7 \%$ self-identified as white. There was a significant difference in the number of white RDs who specialized in eating disorder treatment compared to underrepresented race/ethnicity RDs, $(p<.048)$. The survey results suggest several barriers to the eating disorder specialty were experienced by all dietitians regardless of race/ethnicity. RDs from underrepresented racial/ethnic groups were more likely to report lack of race/ethnic representation as a barrier compared to white RDs $(p<0.022)$.
\end{abstract}

\section{Introduction}

The proportion of dietitians who self-identify as a racial or ethnic minority is significantly lower than the general US population. African American and Hispanic dietitians only make up three and six percent of US dietitians, respectively, while white non-Hispanic dietitians account for $80 \%$ of Registered Dietitians (RDs) (Rogers, 202I). The estimated percentage of Registered Dietitians who identify as a person of color specializing in eating disorders is anecdotally believed to be even less representative of the general population. At the present time, there is little research on why Registered Dietitians choose not to specialize and treat eating disorders, and no research on whether barriers differ for dietitians of color.
In the past, eating disorders (EDs) were perceived as primarily affecting white females; however, research shows that Black adolescents are $50 \%$ more likely to have binging and purging disordered eating behaviors compared to white teenagers (National Eating Disorders Association [NEDA], 2020). Other studies have shown that the risk for developing any type of eating disorder is the same for people of color as compared to white individuals (Cheng et al., 2019). Despite the prevalence of EDs in all communities, disordered eating behavior is less likely to be diagnosed and referred for treatment in minorities (Gordon et al., 2006).

Research supports that patients who see health care providers of their own race feel that they are able to 
communicate more effectively and participate more in their sessions (Cooper-Patrick, 1999). Recent research involving eating disorder treatment demonstrates the potential benefits of culturally-adapted interventions (Scott et al., 2019; Cachelin et al., 2019). One 2019 study looked at the effect of a culturally-adapted program for Latinas with Binge Eating Disorder, and found that those who completed the culturally-adapted program had less frequent binge eating episodes and reductions in depression and psychological distress compared to the control group (Cachelin et al., 2019). With growing evidence of the benefits of culturally competent care, the demographic disparities in the field of nutrition and dietetics is an issue that must be addressed. Therefore, it is important to uncover potential challenges and deterrents for ethnic and racial minorities entering the field of dietetics and what challenges may persist when pursuing the eating disorder specialty.

The present study explored whether additional barriers exist that deter a Registered Dietitian from choosing to specialize in eating disorder treatment. The primary objective was to explore potential barriers or disincentives for those of racial, ethnic, and other marginalized identity groups that might deter individuals from entering this specialty, and whether those perceived barriers differed from dietitians who selfidentify as white.

\section{Methods}

\section{Study Design}

This study used a cross-sectional survey with descriptive and analytic quantitative analysis. The target population was currently credentialed Registered Dietitians. A representative sample of 5,000 RDs was obtained through the Commission on Dietetic Registration (CDR). RDs were sent an email invitation to participate and were asked to consent to participation before entering the survey. An active credential with CDR was the only inclusion criteria, as this allowed comparison of race and ethnicity groups, as well as, enabling comparison between RDs who specialize in eating disorders to those who do not. The study was deemed exempt by Simmons University's Institutional Review Board under federal regulation 45 46.I0I (b) CFR (Office for Human Research Protections [OHRP], n.d.).

\section{Survey Development}

Development of the survey tool was informed by themes from previous studies that investigated adjacent topics (Ozier \& Henry, 2010; Trammell et al., 2016; Wynn et al., 2017), as there is currently no validated survey to answer the proposed research question. Face and content validity was assessed through pretests with collaborating RDs working within the eating disorder specialty. The collaborating RDs provided feedback on race and ethnicity language choice, question formatting, and suggestions for possible barriers to include. The survey questions were primarily close-ended, with limited free-response fields to capture additional barriers. Survey questions were reviewed by CDR as part of the student research project approval process prior to providing a practitioner sample set, to ensure content aligns with CDR and the Academy of Nutrition and Dietetics' mission and vision. Requested revisions made to the survey tool include: changing race and ethnicity categories to match $\mathrm{NIH}$ guidelines, changing practice setting, type, and area to match the Academy's compensation benefits survey (Academy of Nutrition and Dietetics, 2020), and minor formatting changes. The Qualtrics survey was disseminated via email; three subsequent emails were sent to participants as reminders to complete the survey. The survey was active for 14 days from which all data was collected.

\section{Data Collection}

The survey data was collected starting April 30, 202 Ifor a period of 14 days through Qualtrics and all data was downloaded and analyzed in SPSS statistical software (IBM, 2020). Two reminder emails were sent before the survey was closed. Identifiable data was removed prior to importing into SPSS for analysis, and the remaining identifiable data collected through Qualtrics is password protected. No identifiable data was stored outside of the Qualtrics survey tool software. The independent variables of interest were self-reported race and ethnicity of RDs, based on NIH race and ethnicity categorization policies (National Institutes of Health $[\mathrm{NIH}], 2015$ ), and RDs who specialize in eating disorder treatment. The barriers to choosing eating disorder treatment as a specialty within the profession of dietetics was the outcome of interest.

\section{Data Analysis}

All analyses were done in SPSS statistical software. Counts and percentages were calculated for responses to each question. Data was compared and analyzed using Pearson's chi-squared test for categorical data. For the two open-ended survey items, responses were analyzed using a mixed deductive and inductive method. 
Themes and coding were initially determined separately by authors, reconciled, and combined for analysis.

Fifty one participants added a text response in the "other" response field within the question about barriers to working in the ED specialty. Keyword/key phrase analysis was used to categorize and code the free text responses. Keyword analysis determined that responses either fit into an existing category already provided and were re-coded into that category, or the response was excluded because the additional information provided did not relate to a barrier; for example, clarifying the individual's employment history.

The final question of the survey was an open response invitation to provide additional information on pursuing the specialty of eating disorder treatment as an RD. One hundred eleven participants entered a free response answer. Answers were inductively coded using keywords or phrases and eight final categories were determined. Comments that were not relevant to the research question or were determined to be general feedback were coded as 'other' and not included in analyses; 20 out of III (I8\%). Responses that included elements of multiple themes were included in the frequencies of each relevant theme. Representative quotes provided in Table 3 were selected based on frequency, highlighting the most commonly reported themes, phrases and language.

\section{Results}

\section{Participants}

A total of 390 Registered Dietitians responded to the survey out of a sample of 5,000 , resulting in a response rate of $7.8 \%$. Responses that were either incomplete or lacked racial and ethnic background information were excluded from analysis, resulting in a final sample size of 328. The final sample included a higher percentage of white RDs (88.7\%) and female RDs (98.5\%) compared to the currently reported CDR demographics for all RDs (80\% and $92 \%$, respectively). Those who self-identified as a race or ethnicity other than non-Hispanic white were collapsed into a single variable and this group as a whole was compared to RDs that self-identified as nonHispanic white. Complete demographic characteristics are found in Table I.
Table I. Demographic characteristics of respondents $(n=328)$ to a survey on eating disorder specialization in dietetics administered to sample of Registered Dietitian Nutritionists (RDNs) in 2021

\begin{tabular}{|c|c|c|}
\hline \multirow[t]{2}{*}{ Characteristic } & \multicolumn{2}{|c|}{$\begin{array}{c}\text { All Respondents } \\
\text { n (\%) }\end{array}$} \\
\hline & & \\
\hline$\leq 25$ years & 32 & $(9.8)$ \\
\hline $26-35$ years & 118 & $(36.0)$ \\
\hline $36-45$ years & 71 & $(21.6)$ \\
\hline $46-55$ years & 45 & $(13.7)$ \\
\hline $56-65$ years & 46 & $(14.0)$ \\
\hline$\geq 66$ years & 16 & $(4.9)$ \\
\hline \multicolumn{3}{|l|}{ Years practicing as $\mathrm{RD}^{\mathrm{a}}$} \\
\hline$\leq 5$ years & 108 & $(32.9)$ \\
\hline$>5$ years & 220 & $(67.1)$ \\
\hline \multicolumn{3}{|l|}{ Race/ethnicity ${ }^{\mathrm{b}}$} \\
\hline Asian & 14 & $(4.3)$ \\
\hline Black or African American & 9 & $(2.7)$ \\
\hline Indigenous or Alaskan Native & I & $(0.3)$ \\
\hline Hispanic/Latinx & 12 & $(3.7)$ \\
\hline Native Hawaiian/Pacific Islander & 0 & $(0)$ \\
\hline White (non-Hispanic) & 291 & $(88.7)$ \\
\hline Other & 4 & $(1.2)$ \\
\hline \multicolumn{3}{|l|}{ Gender } \\
\hline Female & 323 & $(98.5)$ \\
\hline Male & 4 & $(1.2)$ \\
\hline Non-gender binary & 0 & $(0)$ \\
\hline Transgender female & 0 & $(0)$ \\
\hline Transgender male & 0 & $(0)$ \\
\hline Other & 0 & $(0)$ \\
\hline Preferred not to answer & I & $(0.3)$ \\
\hline \multicolumn{3}{|l|}{ Practice settings ${ }^{\mathrm{b}}$} \\
\hline Acute-care - inpatient & 80 & $(24.5)$ \\
\hline Acute-care - outpatient & 40 & $(12.2)$ \\
\hline $\begin{array}{l}\text { Ambulatory / outpatient care } \\
\text { facility }\end{array}$ & 60 & $(18.3)$ \\
\hline Assisted living or group home & 11 & (3.4) \\
\hline College and university dining & 4 & $(1.2)$ \\
\hline $\begin{array}{l}\text { College, university, or academic } \\
\text { medical center }\end{array}$ & 20 & $(6.1)$ \\
\hline $\begin{array}{l}\text { Contract food management } \\
\text { company }\end{array}$ & 5 & $(1.5)$ \\
\hline Correctional facility & I & $(0.3)$ \\
\hline $\begin{array}{l}\text { Food or equipment manufacturer, } \\
\text { distributor, or retailer }\end{array}$ & 2 & $(0.6)$ \\
\hline Health or fitness facility & 11 & (3.4) \\
\hline Home health & 8 & $(2.4)$ \\
\hline Hospice or palliative care & 4 & $(1.2)$ \\
\hline Long-term care & 46 & $(\mid 4.1)$ \\
\hline Office & 6 & $(1.8)$ \\
\hline Non-governmental organization & 5 & $(1.5)$ \\
\hline
\end{tabular}




\begin{tabular}{|c|c|c|}
\hline $\begin{array}{l}\text { Pharmaceutical or nutrition } \\
\text { products manufacturer, distributor, } \\
\text { or retailer }\end{array}$ & 0 & $(0)$ \\
\hline Private practice & 64 & $(19.6)$ \\
\hline Post-acute or rehab facility & 19 & $(5.8)$ \\
\hline Restaurant & 0 & $(0)$ \\
\hline Retail & 1 & $(0.3)$ \\
\hline School nutrition & 14 & $(4.3)$ \\
\hline $\begin{array}{l}\text { Social services organization } \\
\text { (government or non-government) }\end{array}$ & 24 & $(7.3)$ \\
\hline Sports medicine facility & 3 & $(0.9)$ \\
\hline Surgery center & 3 & $(0.9)$ \\
\hline Trade or professional association & 2 & $(0.6)$ \\
\hline Other (please specify) & 45 & $(13.8)$ \\
\hline \multicolumn{3}{|l|}{ Practice type ${ }^{b}$} \\
\hline $\begin{array}{l}\text { Clinical nutrition - acute care / } \\
\text { inpatient }\end{array}$ & 90 & $(27.4)$ \\
\hline $\begin{array}{l}\text { Clinical nutrition - ambulatory } \\
\text { Care }\end{array}$ & 99 & $(30.2)$ \\
\hline Clinical nutrition - long-term care & 49 & $(14.9)$ \\
\hline Community & 62 & $(18.9)$ \\
\hline Food and nutrition management & 40 & $(12.2)$ \\
\hline Consultation and business & 36 & $(11.0)$ \\
\hline Education and research & 38 & $(11.6)$ \\
\hline $\begin{array}{l}\text { Other position not listed (please } \\
\text { specify) }\end{array}$ & 45 & $(13.7)$ \\
\hline \multicolumn{3}{|l|}{ Practice Areab } \\
\hline Agriculture & 6 & $(1.8)$ \\
\hline Allergy/immunology & 9 & $(2.7)$ \\
\hline Bariatrics & 27 & $(8.2)$ \\
\hline Cardiovascular & 44 & $(13.4)$ \\
\hline College and university dining & 3 & $(0.9)$ \\
\hline Community nutrition/public health & 52 & $(15.9)$ \\
\hline Communications/journalism & 1 & $(0.3)$ \\
\hline Culinary nutrition & 13 & $(4.0)$ \\
\hline Diabetes care & 91 & $(27.7)$ \\
\hline Digital or mobile health & 3 & $(0.9)$ \\
\hline Eating disorders/disordered eating & 78 & $(23.8)$ \\
\hline Food and nutrition consultation & 65 & $(19.8)$ \\
\hline Food safety & 22 & $(6.7)$ \\
\hline Gastroenterological nutrition & 48 & $(14.6)$ \\
\hline Generalist & 49 & $(14.9)$ \\
\hline Gerontological nutrition & 48 & $(14.6)$ \\
\hline Global health & 2 & $(0.6)$ \\
\hline Integrative and functional medicine & & $(5.2)$ \\
\hline Malnutrition & 64 & $(19.5)$ \\
\hline Management & 22 & $(6.7)$ \\
\hline Marketing & 2 & $(0.6)$ \\
\hline Maternal and child health & 29 & $(8.8)$ \\
\hline Media and public relations & 0 & $(0)$ \\
\hline Nutrigenomics & 4 & $(1.2)$ \\
\hline Nutrition and food policy & 12 & (3.7) \\
\hline Nutrition support & 66 & $(20.1)$ \\
\hline
\end{tabular}

\begin{tabular}{llc}
\hline Oncology & 30 & $(9.1)$ \\
\hline Pediatric nutrition & 53 & $(16.2)$ \\
\hline Preventive care/wellness & 43 & $(13.1)$ \\
\hline Quality management & 5 & $(1.5)$ \\
\hline Renal nutrition & 38 & $(11.6)$ \\
\hline School nutrition services & 13 & $(4.0)$ \\
\hline Sports nutrition & 29 & $(8.8)$ \\
\hline Sustainability & 7 & $(2.1)$ \\
\hline Weight management & 85 & $(25.9)$ \\
\hline Other (please specify) & 24 & $(7.3)$ \\
\hline a Aggregated groups for analyses \\
bercents will exceed 100\% due to multiple responses \\
$\quad$ possible
\end{tabular}

\section{Training}

No significant differences were found between white RDs and RDs who identified in underrepresented demographic groups with respect to the level of education and training they received on eating disorders.

\section{Eating Disorder Specialization}

There was a significant difference between the proportion of non-Hispanic white RDs who reported that they specialized in ED treatment compared to RDs who identified as a race or ethnicity other than nonHispanic white $(p=0.048)$.

\section{Barriers}

No significant differences were found between white RDs and RDs who did not identify as non-Hispanic white for the majority of barriers to entry into the specialty of eating disorder treatment. Lack of racial and ethnic representation within the specialty was the only barrier in which there was a significant difference between groups $(p=.022)$. More RDs who identified as an underrepresented minority also reported having experienced racial/ethnic discrimination in the field of dietetics compared to white RDs $(p=.000)$. See Table 2 for barriers.

Significant differences were found between dietitians working in the eating disorder specialty and those not in the specialty. Emotional toll of specialty $(p=.000)$, lack of coursework $(p=.003)$, little professional guidance $(p=.050)$, lack of race and ethnic representation $(p=.000)$, racial and ethnic discrimination in specialty $(p=.001)$, gender based discrimination in specialty $(p=.008)$, not aware of need for RDs in specialty $(p=.000)$, and "did not feel that they would be accepted in specialty" ( $p=.019)$ were all significantly different barriers between RDs specializing in eating disorder treatment and those not in the specialty. 
Table 2. US Registered Dietitian Nutritionists (RDNs) survey responses assessing barriers to specializing in eating disorder treatment, compared across race/ethnicity

\begin{tabular}{|c|c|c|c|}
\hline & $\begin{array}{c}P O C^{a} \\
n=37\end{array}$ & $\begin{array}{l}\text { White (non- } \\
\text { Hispanic) } \\
n=291\end{array}$ & P-value \\
\hline \multicolumn{4}{|l|}{ Perceived barriers to ED treatment ${ }^{\mathrm{a}, \mathrm{b}}$} \\
\hline Emotional toll of specialty & 16 & 126 & .995 \\
\hline Lack of coursework (Bachelors, DPD, Master's) training & 25 & 156 & .108 \\
\hline Little professional guidance (internship, supervision practice) & 20 & 165 & .760 \\
\hline Lack of role models in ED treatment & 8 & 55 & .692 \\
\hline Lack of race/ethnic representation in specialty & 7 & 22 & .022 \\
\hline Racial/ethnic discrimination in specialty & 2 & 10 & .548 \\
\hline Gender-based discrimination in specialty & 0 & 9 & .278 \\
\hline Unable to make time commitments to learning specialty & 9 & 47 & .213 \\
\hline Unable to make financial commitments to learning specialty & 7 & 53 & .917 \\
\hline Not aware of need for RDs in specialty & 4 & 24 & .599 \\
\hline Did not feel I would be accepted in specialty & 0 & 10 & .252 \\
\hline Other & 7 & 44 & .548 \\
\hline None & 4 & 33 & .924 \\
\hline \multicolumn{4}{|l|}{ ED Treatment Specialty } \\
\hline Specializes in ED treatment & 3 & 64 & .048 \\
\hline Does not specialize in ED treatment & 34 & 227 & \\
\hline \multicolumn{4}{|c|}{ Experienced discrimination/challenges in dietetics due to race/ethnicity } \\
\hline Yes & 8 & 4 & .000 \\
\hline
\end{tabular}

- Asian, Black or African American, Indigenous or Alaskan Native, Hispanic/Latinx, Native Hawiian/Pacific Islander, and Other non-white races/ethnicities collapsed into People of Color (POC) variable

b Percents will exceed 100\% due to multiple responses possible

The final question of the survey asked respondents to share any other information as to why an RD might not pursue ED treatment. Respondents provided clarification on why they did not choose to specialize in eating disorders, barriers to pursuing the specialty, and challenges faced in pursuing the specialty. Major themes reported were: lack of training, exposure, or guidance, complex population \& emotional burden, not in RD scope of practice, weight bias \& size discrimination in specialty, personal history with ED, lack of mentors, lack of finances or time, and racial, LGBTQ+, or age discrimination in specialty. Frequencies of each response and selected quotes from each major theme are provided in Table 3. 
Table 3. Themes identified from open-ended question on barriers/deterrents to eating disorder specialty $n=I I I$

\section{Themes}

Lack of training, exposure, or

44 (39.6) "There was little to no emphasis at the undergraduate level on studying ED guidance treatment and I can't recall any experience during my internship."

"The biggest barrier for specializing in ED is the fact that when you're exploring dietetics as a whole you do not have much exposure to it. Unfortunately it is nearly impossible to shadow a dietitian specializing in ED due to privacy concerns. Therefore for me, there was less information to go off of when deciding what I wanted to do as a dietitian."

"I wasn't given an opportunity to learn about it during my coursework or internship. Wouldn't know where to start now."

$\begin{array}{lll}\text { Complex } & \text { I5 (13.5) } & \text { "I recall the mental toll of being an eating disorder specialist being driven home and } \\ \text { population \& } & \text { closed the door on that option for me right away, would have been interesting to } \\ \text { emotional burden } & & \text { hear more perspectives earlier on." } \\ & \text { "I know myself and other dietitians have expressed frustration working with patients } \\ & \text { with ED as it is very complex and requires multiple disciplinary involvement for } \\ & \text { treatment to be effective, particularly psychiatric treatment." } \\ & \text { "It's an awesome specialty to pursue, but very hard and emotionally taxing." }\end{array}$

Not in RDN

Scope of practice

$10(9.0)$ recovery mode could benefit from nutrition ed provided by RDs, but while in an acute state I don't see that RDs can do much beyond assessment.

EDs are more of a psychology specialty in my mind. Not to say RDs shouldn't do this job but it seems like you would have to do a LOT of extra counseling coursework to get to a point where you are comfortable counseling someone with an ED.

Weight bias \& size $10(9.0)$
discrimination in
specialty

$\begin{aligned} & \text { Personal history } \\ & \text { with ED }\end{aligned}$

"We receive next to no education when it comes to eating disorders in school. Additionally, the heavy emphasis on weight management within the dietetics field is extremely harmful."

"I have experienced discrimination as a Registered Dietitian of size. I would LOVE to see focus on eating disorders in undergraduate and graduate coursework. I would also like to see a change in curriculum moving away from weight stigmatization within the general nutrition community. I never heard about HAES or IE until I was in graduate school."

"I think it is also important to recognize size discrimination in the dietetics profession generally and related to ED."

with ED

"In my experience many students shy away from it out of fear unless they're comfortable with psychiatric conditions or have their own history of an eating disorder."

"I, myself, continued to have some disordered patterns re food and eating. I am not sure that it would have been best for me to work only with ED clients/patients. ED practice may have been an unhealthy immersion for me."

"I had an eating disorder as an adolescent but did not find a lot of opportunity to learn more about it as I studied nutrition."

\begin{tabular}{lll}
\hline $\begin{array}{l}\text { Lack of mentors } \\
\text { (5.4) }\end{array}$ & $\begin{array}{l}\text { "Very hard to identify mentors who are people of color." } \\
\text { "More preceptors as needed across the country in this area as this is a rising concern } \\
\text { in our culture." }\end{array}$ \\
$\begin{array}{l}\text { Lack of finances or } 5 \text { (4.5) } \\
\text { time }\end{array}$ & $\begin{array}{l}\text { "Cost and time are the two biggest factors for me." } \\
\text { "In the beginning, I felt the ED certification was costly and very time consuming. I felt } \\
\text { like I could not justify it based on the resources that I had available." }\end{array}$ \\
$\begin{array}{l}\text { Racial, LGBTQ+, } \\
\text { or age } \\
\text { discrimination in } \\
\text { specialty }\end{array}$ & $\begin{array}{l}\text { "Since I am older and above normal weight I feel that would be a hindrance to me } \\
\text { working with the ED population." } \\
\text { "Programs tend to be fat phobic and ignore social injustice. The decision to attend } \\
\text { workshops and programs that are unethical is a real challenge, given there are } \\
\text { minimal options." } \\
\text { "More edu about racial, LGTB+ issues, harm reduction." }\end{array}$
\end{tabular}




\section{Discussion}

The findings from this study suggest several barriers to the eating disorder specialty within the dietetics profession that prevent RDs in general from pursuing this area of practice. The findings further suggest that dietitians of color may experience additional barriers to the specialty, such as racial discrimination in the profession and lack of racial and ethnic representation in ED treatment. Overall, our findings suggest that dietitians who identified in an underrepresented racial or ethnic group were less likely to specialize in ED treatment.

Across all respondents, frequently reported barriers to specializing in eating disorder treatment were similar to barriers found to entering the profession of dietetics. Lack of professional guidance and an inability to make financial and time commitments to the training and education have been previously reported as barriers to entering the profession of dietetics (Felton et al., 2008; Heiss et al., 2012; Whelan et al., 2017; White, 2013), and persisted as barriers to the eating disorder specialty once someone became an RD. Weight stigma and body size discrimination within the profession were common themes in the survey free responses, which had also been previously reported as barriers to entering the dietetics profession (Felton et al., 2008; Heiss et al., 2012; Whelan et al., 2017). This barrier may be especially discouraging for eating disorder specialization due to the nature of the area of practice. Similar to Whelan et al.'s findings, many respondents commented on the weightcentric focus in dietetics education and practice as a challenge for dietitians treating eating disorders (2017).

A number of barriers were identified by respondents in this study that were also reported in previous studies assessing challenges dietitians faced specifically in treating individuals with eating disorders (Ozier \& Henry, 2010; Trammell et al., 2016). A lack of eating disorder coursework within dietetics curriculums, as well as a lack of dedicated professional training with clear guidance on how to become an ED RD, were frequently discussed barriers in this study and have been reported as barriers in previous research (Ozier \& Henry, 2010; Trammell et al., 2016). Additionally, an RDs' personal experience and history with eating disorders was a commonly reported deterrent (Ozier \& Henry, 2010; Trammell et al., 2016). Additional barriers specific to treatment of eating disorders from open-ended responses suggested that some respondents felt that eating disorder treatment is primarily a mental health concern, and was either outside an RDs scope of practice or required specialized training in psychology. This shows a need for clarification of the RD role in treating eating disorders, dedicated coursework, and professional training in treatment of eating disorders.

Responses to open prompts in this survey found several barriers that have not been previously identified. Themes from open responses included the complexity of eating disorder work and the emotional toll involved. Some RDs were simply not interested in the specialty due to these burdens, while others noted the need for mentorship and stressed the importance of additional training. Lack of available jobs was also a theme among free-responses, with some noting difficulty due to location within the United States or area of practice, resulting in limited training opportunities. These barriers further support the need for a clear, well-defined path to the eating disorder treatment specialty that begins with exposure in dietetics curriculums.

Based on previous research of known barriers for racial and ethnic minority groups entering the dietetics profession (Edgoose et al., 2019), we hypothesized that barriers would differ between white RDs and RDs who did not identify as non-Hispanic white. However, we found no significant differences apart from lack of racial and ethnic representation in the eating disorder specialty. A potential explanation for these findings may have been that the small sample size limited the study's power to detect a difference. Additional research should be done to further explore barriers faced by RDs of underrepresented racial and ethnic groups in pursuing specialty areas of the field.

The strengths of this study include exploring the novel topic of perceived barriers to eating disorder treatment with a focus on differences by race and ethnicity, as well as a random sample sizable enough to find statistically significant differences by race and ethnicity. However, there were also several limitations. Because of the novelty of the topic, there have been no validated survey tools that could have been used in this research. Survey development was informed by similar studies and input from key informants, but the validity and reliability of the tool has not been defined. Compared with current demographic statistics from CDR, this study sample also had a slightly higher proportion of white respondents (88.7\% compared to $80 \%$ ) and male respondents (I.2\% 
compared to 3.7\%). Though not drastically different, the results may be affected by the representativeness of the sample. In future research, a larger sample size would be beneficial in comparing differences in perceived barriers between all races and ethnic groups instead of only comparing white RDs and RDs who identify in an underrepresented racial or ethnic group.

\section{Conclusion}

The survey results suggest several barriers to the eating disorder specialty within the dietetics profession, which may be disproportionately impacting RDs who identify in an underrepresented race or ethnic group. Barriers to the dietetics profession and the ED specialty, and differences by race and ethnicity, suggest a need for systematic changes. Increased formal training, guidance, and race and ethnic diversity may reduce the perceived barriers to the ED specialty for RDs of underrepresented racial and ethnic groups especially.

\section{Author Bios}

Megan Bradshaw is a graduate student at Simmons University in Boston, MA, with plans to begin the dietetic internship in the fall of 2022. Megan intends to focus her RDN career in eating disorder treatment, and currently volunteers with the National Eating Disorder Association. She has a background in research grant administration and finance.

Sienna Caron is a dietetic intern at the University of Saint Joseph Connecticut, USA. Sienna's research interests focus on eating disorders, particularly related to relative energy deficiency in sport.

Dr. Lisa S. Brown is an associate professor of nutrition and the dietetic internship director at Simmons University in Boston, MA. Her professional service includes serving as the current chair of the Massachusetts Licensure Board for Nutritionists and Dietitians, and has served as the Diversity Liaison for the Religion Member Interest Group (RMIG) of the Academy of Nutrition and Dietetics.

\section{References}

Cachelin, F. M., Gil-Rivas, V., Palmer, B., Vela, A., Phimphasone, P., de Hernandez, B. U., \& Tapp, H. (2019). Randomized controlled trial of a culturally-adapted program for latinas with binge eating. Psychological Services, 16(3), 504-512. https://doi.org/10.1037/ser0000182

Cheng, Z. H., Perko, V. L., Fuller-Marashi, L., Gau, J. M., \& Stice, E. (2019). Ethnic differences in eating disorder prevalence, risk factors, and predictive effects of risk factors among young women. Eating Behaviors, 32, 23-30. https://doi. org/10.1016/j.eatbeh.2018.11.004

Academy of Nutrition and Dietetics. (2020). Compensation \& Benefits Survey of the Dietetics Profession 2019. https://www. jandonline.org/article/S2212-2672(19)31804-0/pdf

Cooper-Patrick, L. (1999). Race, gender, and partnership in the patient-physician relationship. JAMA, 282(6), 583. https://doi.org/10.1001/jama.282.6.583

Edgoose, J., Steinkamp, L., Vang, K., Hampton, A., \& Dosch, N. (2019). A Qualitative Study of Undergraduate Racial and Ethnic Minority Experiences and Perspectives on Striving to Enter Careers in the Health Professions. WMJ : official publication of the State Medical Society of Wisconsin, II8(2), 60-64. https://wmjonline.org//18no2/edgoose/

Felton, T. M., Nickols-Richardson, S. M., Serrano, E., \& Hosig, K. W. (2008). African-American students' perceptions of their majors, FUTURE professions, and The DIETETICS major and Profession: A qualitative analysis. Journal of the American Dietetic Association, 108(7), 1192-1197. https:// doi.org/l0.1016/j.jada.2008.04.022

Gordon, K. H., Brattole, M. M., Wingate, L. R. R., \& Joiner, T. E. (2006). The impact of Client race on Clinician detection of eating disorders. Behavior Therapy, 37(4), 319-325. https:// doi.org/10.1016/j.beth.2005.12.002

Heiss, C. J., Henley, S. M., Daniluk, P., Rengers, B., Fajardo-Lira, C., Gillette, C. D., \& Bizeau, M. (2012). Recruiting Hispanics to dietetics: WIC educators' perceptions of the profession. Journal of Allied Health, 4I(4), e79-e82. https://pubmed. ncbi.nlm.nih.gov/23224288/

IBM. (2020). SPSS StatisticsVersion (28).

Office for Human Research Protections (OHRP). (2021, June 16). 45 CFR 46. HHS.gov. https://www.hhs.gov/ohrp/ regulations-and-policy/regulations/45-cfr-46/index.html

National Eating Disorders Association (n.d.) People of Color and Eating Disorders. https://www.nationaleatingdisorders. org/people-color-and-eating-disorders

Ozier, A. D., \& Henry, B. W. (2010). Preliminary report on dietitians' views and confidence related to nutrition care for eating disorders. ICAN: Infant, Child, \&amp; Adolescent Nutrition, 2(2), 106-III. https://doi. org/10.1177/194/406409359536 
Rogers, D. (202I). Report on the Academy/Commission on Dietetic Registration 2020 NEEDS satisfaction survey. Journal of the Academy of Nutrition and Dietetics, $121(\mathrm{I})$, 134-138. https://doi.org/10.1016/j.jand.2020.10.018

Scott, T. N., Gil-Rivas, V., \& Cachelin, F. M. (2019). The need for cultural adaptations to health interventions for African AMERICAN women: A qualitative analysis. Cultural Diversity and Ethnic Minority Psychology, 25(3), 33I-34l. https://doi.org//0.1037/cdp0000228

Trammell, E. L., Reed, D., \& Boylan, M. (2016). Education and practice gaps of registered dietitian nutritionists working with clients with eating disorders. Topics in Clinical Nutrition, 3I(I), 73-85. https://doi.org//0.1097/ tin.0000000000000059

U.S. Department of Health and Human Services. (2015, April 8). NOT-OD-15-089: Racial and Ethnic categories and definitions for $\mathrm{NIH}$ diversity programs and for other reporting purposes. National Institutes of Health. https://grants.nih. gov/grants/guide/notice-files/not-od-I5-089.html.

Whelan, M., Ridgeway, M., \& Yerrick, R. K. (2017). Pushing past Clichés: Latina and Black Women's perceptions of The DIETETICS major and profession during career exploration. Journal of Latinos and Education, 17(2), 164178. https://doi.org/10.1080/15348431.2017.1303772

White, J. (2013). "Hearing the Voices": African American Nutrition Educators Speak about Racism in Dietetics. Journal of Critical Dietetics, I (3), 26-35. https://criticaldieteticsblog. com/2013/04/02/hearing-the-voices-african-americannutrition-educators-speak-about-racism-in-dietetics/

Wynn, C. L., Raj, S., Tyus, F., Greer, Y. D., Batheja, R. K., Rizwana, Z., \& Hand, R. K. (2017). Barriers to and facilitators of Dietetics education among students of DIVERSE backgrounds: Results of a survey. Journal of the Academy of Nutrition and Dietetics, 117(3), 449-468. https://doi.org/10.1016/j.jand.2016.06.010 